\title{
High prevalence of non-dipping patterns among Black Africans with uncontrolled hypertension: a secondary analysis of the CREOLE trial
}

Prossie Merab Ingabire ${ }^{1,2^{*}}$, Dike B. Ojji ${ }^{4,5}$, Brian Rayner ${ }^{9}$, Elijah Ogola ${ }^{13}$, Albertino Damasceno ${ }^{14}$, Erika Jones ${ }^{9}$, Anastase Dzudie ${ }^{15}$, Okechukwu S. Ogah ${ }^{7}$, Neil Poulter ${ }^{11}$, Mahmoud U. Sani ${ }^{8}$, Felix Ayub Barasa ${ }^{12}$, Grace Shedul ${ }^{6}$, John Mukisa2 ${ }^{2}$ David Mukunya ${ }^{2,3}$, Bonnie Wandera², Charles Batte ${ }^{2}$, James Kayima², Shahiemah Pandie ${ }^{10}$ and Charles Kiiza Mondo ${ }^{1}$ CREOLE Study Investigators

\begin{abstract}
Background: Dipping of blood pressure (BP) at night is a normal physiological phenomenon. However, a non-dipping pattern is associated with hypertension mediated organ damage, secondary forms of hypertension and poorer long-term outcome. Identifying a non-dipping pattern may be useful in assessing risk, aiding the decision to investigate for secondary causes, initiating treatment, assisting decisions on choice and timing of antihypertensive therapy, and intensifying salt restriction.
\end{abstract}

Objectives: To estimate the prevalence and factors associated with non-dipping pattern and determine the effect of 6 months of three antihypertensive regimens on the dipping pattern among Black African hypertensive patients.

Methods: This was a secondary analysis of the CREOLE Study which was a randomized, single blind, three-group trial conducted in 10 sites in 6 Sub-Saharan African countries. The participants were 721 Black African patients, aged between 30 and 79 years, with uncontrolled hypertension and a baseline 24-h ambulatory blood pressure monitoring (ABPM). Dipping was calculated from the average day and average night systolic blood pressure measures.

Results: The prevalence of non-dipping pattern was 78\% (564 of 721). Factors that were independently associated with non-dipping were: serum sodium $>140 \mathrm{mmol} / \mathrm{I}(\mathrm{OR}=1.72,95 \% \mathrm{Cl} 1.17-2.51, p$-value 0.005$)$, a higher office systolic $\mathrm{BP}(\mathrm{OR}=1.03,95 \% \mathrm{Cl} 1.01-1.05, p$-value 0.003$)$ and a lower office diastolic $\mathrm{BP}(\mathrm{OR}=0.97,95 \% \mathrm{Cl} 0.95-0.99$, $p$-value 0.03). Treatment allocation did not change dipping status at 6 months (McNemar's Chi ${ }^{2} 0.71, p$-value 0.40).

Conclusion: There was a high prevalence of non-dipping among Black Africans with uncontrolled hypertension. ABPM should be considered more routinely in Black Africans with uncontrolled hypertension, if resources permit, to help personalise therapy. Further research is needed to understand the mechanisms and causes of non-dipping pattern and if targeting night-time BP improves clinical outcomes.

Trial registration ClinicalTrials.gov (NCT02742467).

Keywords: Non-dipping pattern, Dipping pattern, Uncontrolled hypertension, Black African

*Correspondence: prossienkundiye@gmail.com

1 St. Francis Hospital, Nsambya, Kampala, Uganda

Full list of author information is available at the end of the article

(c) The Author(s) 2021. Open Access This article is licensed under a Creative Commons Attribution 4.0 International License, which permits use, sharing, adaptation, distribution and reproduction in any medium or format, as long as you give appropriate credit to the original author(s) and the source, provide a link to the Creative Commons licence, and indicate if changes were made. The images or other third party material in this article are included in the article's Creative Commons licence, unless indicated otherwise in a credit line to the material. If material is not included in the article's Creative Commons licence and your intended use is not permitted by statutory regulation or exceeds the permitted use, you will need to obtain permission directly from the copyright holder. To view a copy of this licence, visit http://creativecommons.org/licenses/by/4.0/. The Creative Commons Public Domain Dedication waiver (http://creativeco mmons.org/publicdomain/zero/1.0/) applies to the data made available in this article, unless otherwise stated in a credit line to the data. 


\section{Background}

Hypertension is the leading risk factor for mortality accounting for approximately 10 million deaths and 218 DALYs annually [1]. The prevalence of hypertension has increased in Africa from approximately 20\% in 1990 to over $30 \%$ in 2010 , and more than $30 \%$ of these hypertensive individuals are not aware of their diagnosis, demonstrating a huge burden of undiagnosed and uncontrolled hypertension [2, 3]. In a meta-analysis by Ataklte et al., about $18 \%$ of individuals with hypertension in Sub-Saharan Africa were receiving treatment across the studies, and only $7 \%$ had controlled blood pressure, highlighting the need for implementation of timely and appropriate strategies for diagnosis, control, and prevention [3].

Even though office blood pressure (BP) measurement has remained the standard of BP measurement globally, it gives limited information on the biological rhythms inherent to the disease process [4-6]. Ambulatory Blood Pressure monitoring (ABPM) is now the recommended method for diagnosing hypertension and assessing long term outcomes[7]. ABPM is more precise because it takes more measurements in periods containing the main sources of BP variability [6]. The mean 24-h, daytime, and night-time indicators have classically been used for both the relationship between ambulatory BP and cardiovascular prognosis, as well as for assessing the antihypertensive effect of drugs [4-6, 8-13].

Furthermore, ambulatory BP readings also provide information on the dipping status [7]. Dipping of BP in the night is a normal physiological process that is due to the reduction in sympathetic tone and the parallel increase in vagal activity during the sleep period. A reduction of $>10 \%$ to $20 \%$ in systolic and diastolic BP in the night, compared to daytime readings, is defined as normal dipping. Patients with a nocturnal reduction $>20 \%$ are defined as extreme dippers, while those with $<10 \%$ reduction BP levels are defined as non-dippers. On the other hand, reverse dippers or risers are those with a paradoxical rise in the night BP [14-16].

Non-dipping pattern is associated with hypertension mediated organ damage (HMOD), secondary forms of hypertension and poorer long-term outcomes [17-20]. Identifying a non-dipping pattern may be useful in assessing risk, aiding the decision to investigate for secondary causes, initiate treatment, assist decisions on choice and timing of antihypertensive therapy, and intensifying salt restriction.

Treatment based on dipping status is an emerging novel concept for identifying high-risk hypertensive patients who would derive maximum benefit with antihypertensive medication [21]. Unfortunately, the diagnostic and prognostic importance of dipping patterns has not been widely adopted in Sub-Saharan Africa, probably because of limited resources [22].

\section{Methods \\ Study aims}

Therefore, this study aimed to describe the dipping patterns of Black African patients with hypertension and determine whether antihypertensive therapy leads to a change of dipping status at 6 months of therapy in a posthoc analysis of the CREOLE trial [23, 24].

\section{Study design}

The CREOLE Trial was a multicenter, single-blind randomized trial comparing dual therapies of amlodipine plus hydrochlorothiazide, amlodipine plus perindopril and perindopril plus hydrochlorothiazide for lowering BP in Black Africans. The detailed study methods have been previously described [23, 24]. With relevant ethics approval and written informed consent from participating sites and participants, respectively, the trial was prospectively registered and updated at ClinicalTrials.gov (NCT02742467). We performed a secondary analysis of the CREOLE dataset to estimate the prevalence and factors associated with non-dipping pattern and determine the effect of 6 months of antihypertensive therapy on the dipping pattern among Black African hypertensive patients.

\section{Study setting}

This study was conducted in 10 centers in 6 Sub-Saharan African countries between June 2017 and June 2018. The study sites were in Abuja, Ibadan and Kano in Nigeria, Cape Town, South Africa, Eldoret and Nairobi in Kenya, Maputo in Mozambique, Douala in Cameroon and Kampala in Uganda.

\section{The CREOLE trial (the primary study)}

This was a multicenter study, whose rational and design have been previously published [23, 24]. Briefly, eligible patients were randomized to three arms of dual antihypertensive therapy: a daily regimen of $5 \mathrm{mg}$ of amlodipine plus $12.5 \mathrm{mg}$ of hydrochlorothiazide, $5 \mathrm{mg}$ of amlodipine plus $4 \mathrm{mg}$ of perindopril, or $4 \mathrm{mg}$ of perindopril plus $12.5 \mathrm{mg}$ of hydrochlorothiazide for 2 months. Doses were then doubled (10 and $25 \mathrm{mg}, 10$ and $8 \mathrm{mg}$, and 8 and $25 \mathrm{mg}$, respectively) for an additional 4 months.

\section{Study participants}

Data of the 721 Black African patients with uncontrolled hypertension enrolled in the randomized trial that had a 24-h ambulatory BP measurement at baseline were analyzed in this study. 


\section{Study procedure}

Enrolled patients had a 24-h ABPM using a validated device (Meditech monitor [ABPM-05 model] and Meditech BP cuff) at the baseline and 6 months' study visits. Patients wore the ABPM device for a minimum of $24 \mathrm{~h}$ with automatic readings every $30 \mathrm{~min}$ in the daytime and hourly at night. Daytime was defined as 9 am through $9 \mathrm{pm}$, and night-time as 12 midnight through 6 am. Small, medium or large blood pressure cuffs were utilized as appropriate on the non-dominant arm. Acceptable criteria of ABPM were $24 \mathrm{~h}$ measurement with at least $80 \%$ of available readings.

Patients were reviewed every 2 months but ABPM was only done at baseline and 6 months visits. Office $\mathrm{BP}$ was measured at every study visit.

Blood samples for serum creatinine, urea, random blood sugar, lipid profile and full blood count were collected at baseline and 6 months visits.

\section{Data analysis}

Participants were grouped by baseline dipping category into extreme dippers, dippers, non-dippers and reverse dippers. The dipping category was assessed using the calculated difference between daytime mean systolic BP and nighttime mean systolic BP expressed as a percentage of the mean daytime systolic BP value at each visit. The dipping values were later dichotomized into nondippers (dipping values $<10 \%$ ) and dippers (dipping values $\geq 10 \%$ ) at both baseline and 6 months.

Baseline continuous variables including age in years, body mass index (BMI), average office heart rate, average office systolic BP, average office diastolic BP, fasting blood glucose, serum creatinine and eGFR, serum urea, serum sodium, serum potassium, high density lipoprotein (HDL), low density lipoprotein (LDL), total cholesterol, triglycerides (TG), blood hemoglobin concentration and white blood cell count, were extracted from the primary data set and summarized as means and standard deviations.

Baseline categorical variables including gender, history of smoking, history of diabetes mellitus, history of alcohol use, duration of hypertension (below and above 1 year), age category (above and below 55 years) and treatment arm randomized to, were extracted from the primary data set and summarized as percentages.

Comparison of the participant baseline characteristics between the two dipping categories (non-dippers and dippers) was performed using T-test for the continuous variables and chi-squared test or appropriate non-parametric tests for categorical characteristics based on their distribution.
Multivariable logistic regression analysis was used to identify predictors of non-dipping status. Predictors of non-dipping status included in the final multivariable model were chosen a priori based on published literature.

To determine the effect of antihypertensive therapy on the dipping category we conducted the McNemar's test for the patients who had both the baseline and 6 months ambulatory BP measurements done. Subgroup analysis using McNemar's test was also conducted in the three randomized treatment arms to determine if any of the antihypertensive therapies had effect on the dipping category.

\section{Results}

\section{Participant characteristics}

The study cohort included 721 participants with 454 (63\%) females. The mean age was $51.0 \pm 10.8$ years. Of the 721 participants, 371 (51\%) had been diagnosed with hypertension for less than one year. Only $39(5 \%)$ had diabetes mellitus. There were 14 (1.9\%) current smokers and $160(22 \%)$ were current users of alcohol.

\section{Prevalence of different dipping patterns using systolic ABPM}

Among the 728 randomized patients in the trial, 721 patients had a complete ABPM at baseline and were included in the secondary analysis.

The non-dippers accounted for 385 (53\%) of the study population, reverse dippers for 179 (25\%), dippers for 142 (20\%), and the extreme dippers for $15(2 \%)$. The prevalence of non-dipping (non-dippers and reverse dippers) was $78 \%$ (Fig. 1).

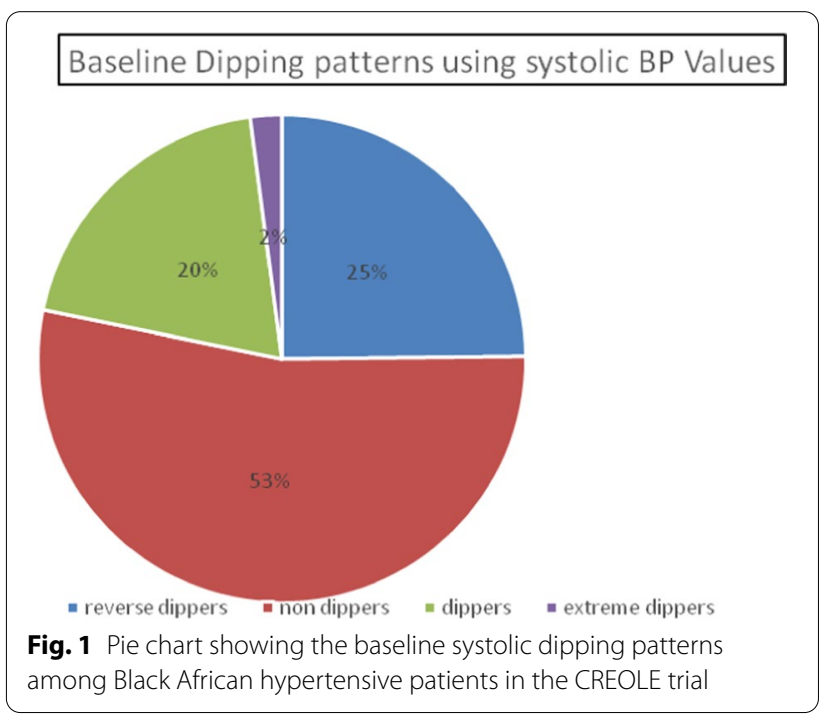




\section{Baseline characteristics among the non-dippers} and the dippers

We compared the baseline characteristics of the non-dippers (non-dippers and reverse dippers, 78\%) with dippers (extreme dippers and dippers, $22 \%$ ) by univariate analysis (Table 1 ). The non-dippers were significantly

Table 1 Baseline characteristics among 721 Black African hypertensive patients in the CREOLE trial based on dipping pattern

\begin{tabular}{|c|c|c|c|}
\hline Variable & Non-dippers $N=564$ (78\%) & Dippers N = 157 (22\%) & $P$ value \\
\hline Age, years & $52 \pm 11$ & $48 \pm 10$ & 0.001 \\
\hline Gender, female & $353(63)$ & $101(64)$ & 0.689 \\
\hline $\mathrm{BMI}^{\mathrm{e}} \mathrm{kg} / \mathrm{m}^{2}<25$ (normal) & $152(27)$ & $48(30)$ & \\
\hline $25-<30$ (overweight) & $207(37)$ & $64(41)$ & \\
\hline$\geq 30$ (obese) & $204(36)$ & $45(29)$ & 0.210 \\
\hline \multicolumn{4}{|l|}{ Treatment arm } \\
\hline Amlodipine and hydrochlorothiazide & $194(34)$ & $49(31)$ & 0.245 \\
\hline Amlodipine and perindopril & $191(34)$ & $47(30)$ & \\
\hline Perindopril and hydrochlorothiazide & $179(32)$ & $61(39)$ & \\
\hline Hypertension duration $<1$ year & $285(51)$ & $86(55)$ & 0.347 \\
\hline Diabetes mellitus & $36(6)$ & $3(2)$ & 0.027 \\
\hline Current smoking & $56(10)$ & $15(10)$ & 0.889 \\
\hline Current alcohol use & $196(35)$ & $37(24)$ & 0.008 \\
\hline Office heart rate, beats/minute & $82 \pm 14$ & $80 \pm 13$ & 0.148 \\
\hline Office systolic BP, mmHg & $160 \pm 11$ & $158 \pm 10$ & 0.041 \\
\hline Office diastolic BP, mmHg & $98 \pm 10$ & $99 \pm 8$ & 0.144 \\
\hline Day ambulatory systolic $\mathrm{BP}, \mathrm{mmHg}$ & $149 \pm 1$ & $148 \pm 1$ & 0.780 \\
\hline Night ambulatory systolic BP, mmHg & $146 \pm 1$ & $127 \pm 1$ & 0.000 \\
\hline Day ambulatory diastolic BP, $\mathrm{mmHg}$ & $91 \pm 0$ & $93 \pm 1$ & 0.091 \\
\hline Night ambulatory diastolic BP, $\mathrm{mmHg}$ & $86 \pm 1$ & $76 \pm 1$ & 0.000 \\
\hline Serum sodium ${ }^{c}, \mathrm{mmol} / \mathrm{L} \leq 140$ & $284(51)$ & $97(63)$ & \\
\hline$>140$ & $272(49)$ & $58(37)$ & 0.011 \\
\hline Serum potassium ${ }^{\mathrm{d}}, \mathrm{mmol} / \mathrm{L} \leq 4.0$ & $243(43)$ & $66(42)$ & \\
\hline$>4.0$ & $319(57)$ & $91(58)$ & 0.788 \\
\hline Estimated glomerular filtration rate ${ }^{\mathrm{d}}, \mathrm{ml} / \mathrm{min} \geq 60$ & $539(96)$ & $153(97)$ & \\
\hline$<60$ & $23(4)$ & $4(3)$ & 0.480 \\
\hline Serum urea, $\mathrm{mmol} / \mathrm{L} \leq 7.1$ & $411(77)$ & $128(83)$ & \\
\hline$>7.1$ & $121(23)$ & $26(17)$ & 0.119 \\
\hline Fasting blood sugar, mmol/L & $5.4 \pm 1.9$ & $5.2 \pm 1.1$ & 0.219 \\
\hline Low density lipoprotein ${ }^{\mathrm{a}}$, $\mathrm{mmol} / \mathrm{L} \leq 2.6$ & $173(36)$ & $53(38)$ & \\
\hline$>2.6$ & $303(64)$ & $85(62)$ & 0.658 \\
\hline Total cholesterol, $\mathrm{mmol} / \mathrm{L} \geq 5.2$ & $328(68)$ & $89(64)$ & \\
\hline$>5.2$ & $152(32)$ & $51(36)$ & 0.291 \\
\hline High density lipoprotein, $\mathrm{mmol} / \mathrm{L} \leq 1.0$ & $139(29)$ & $51(36)$ & \\
\hline$>1.0$ & $341(71)$ & $89(64)$ & 0.092 \\
\hline Triglycerides, $\mathrm{mmol} / \mathrm{L} \leq 1.70$ & $317(66)$ & $88(63)$ & \\
\hline$>1.70$ & $162(34)$ & $51(37)$ & 0.531 \\
\hline Haemoglobin ${ }^{b}, g / d l \leq 12$ & $77(20)$ & $14(15)$ & \\
\hline$>12$ & $309(80)$ & $80(85)$ & 0.262 \\
\hline White blood cell count, ${ }^{*} 10^{9} / \mathrm{L}$ & $5.8 \pm 1.8$ & $6.1 \pm 2.1$ & 0.186 \\
\hline
\end{tabular}

a 107 missing values

b 241 missing

' 3 missing values and estimated glomerular filtration rate was calculated based on the ckd-epi creatinine equation

$\mathrm{d} 2$ missing values

e 1 missing value 
older ( $p$-value 0.0009); more likely to use alcohol, ( $p$-value $0.008)$ and suffer from diabetes $(p=0.027)$. Additionally, the non-dippers had significantly higher office systolic BP ( $p$-value 0.041$)$ and serum sodium ( $p$-value 0.004$)$; and significantly lower serum haemoglobin ( $p$-value 0.009 ).

There was no difference in dipping status between males and females, in lipid profile, smoking status and kidney function.

\section{Predictors of non-dipping pattern among Black Africans with Hypertension}

On multivariable logistic regression, only the serum sodium $>140 \mathrm{mmol} / \mathrm{L}$, a higher office systolic BP and lower office diastolic BP were significantly associated with non-dipping pattern. Individuals with serum sodium $>140 \mathrm{mmol} / \mathrm{L}$ were 1.72 times as likely to be non-dippers as compared to dippers (95\% CI 1.17-2.51, $p$-value 0.005). A unit increase in office systolic BP was associated with 1.03 times the odds of being a non-dipper

Table 2 Independent predictors of non-dipping pattern after logistic regression

\begin{tabular}{llll}
\hline Variable & Adjusted odds ratio & $\mathbf{9 5 \%} \mathbf{C l}$ & $\boldsymbol{p}$-value \\
\hline $\begin{array}{l}\text { Serum sodium, mmol/L } \\
\leq 140\end{array}$ & Reference & & \\
$>140$ & 1.72 & $1.17-2.51$ & 0.005 \\
$\begin{array}{l}\text { Serum urea, mmol/L } \\
\leq 7.1\end{array}$ & Reference & & \\
$>7.1$ & 1.56 & $0.95-2.54$ & 0.076 \\
$\begin{array}{l}\text { Treatment arm } \\
\text { Amlodipine plus HCTZ }\end{array}$ & Reference & & \\
Amlodipine plus perin- & 1.13 & & \\
$\quad$ dopril & & $0.71-1.81$ & 0.598 \\
Perindopril plus HCTZ & 0.73 & & \\
Age category & & $0.47-1.13$ & 0.158 \\
$\leq 55$ years & Reference & & \\
$\quad<55$ years & 0.77 & $0.50-1.17$ & 0.220 \\
Office systolic BP & 1.03 & $1.01-1.05$ & 0.003 \\
Office diastolic BP & 0.97 & $0.95-0.99$ & 0.030 \\
Office heart rate & 1.01 & $0.99-1.03$ & 0.130 \\
\hline
\end{tabular}

as compared to being a dipper (95\% CI 1.01 to 1.05 , $p$-value 0.003). A unit increase in office diastolic BP was associated with 0.97 times the odds of being a non-dipper as compared to being a dipper (95\% CI 0.95 to 0.99 , $p$-value 0.03$)$. There was no association with treatment allocation (Table 2).

\section{Change of dipping pattern following 6 months of antihypertensive therapy}

Of the 721 patients who had a complete ABPM at baseline, only 619 had a complete ABPM at 6 months. Following the antihypertensive therapy, 19\% (91/487) changed from non-dippers at baseline to dippers at 6 months and $61 \%(80 / 132)$ changed from dippers at baseline to nondippers at 6 months. This was not statistically significant; McNemar's $\mathrm{Chi}^{2}$ 0.71, $p$ value 0.400 . Even after stratification in the different treatment arms there was no statistically significant change in the dipping category (Table 3 ).

\section{Discussion}

A large proportion of African hypertensive patients are non-dippers. Previous studies have reported a varying prevalence of non-dipping pattern ranging from 36 to $89 \%$ depending on the group studied [25-35]. In addition, two previous studies showed that black patients are more likely to have a higher percentage of a non-dipping pattern than patients of other races [36, 37]. Hebert et al. showed a higher prevalence of non-dipping pattern of $63 \%$ among African Americans compared to $47 \%$ in European Americans [36].

The high prevalence of a non-dipping pattern in our study may be explained by the fact that all the patients randomized had uncontrolled hypertension, as poorly treated hypertension has been linked to non-dipping pattern [34]. For example, Ben-Dov et al. in their study of well treated hypertensive patients found a prevalence for non-dipping pattern of 37\% [30]. Second, half of our patients had been diagnosed with hypertension for more than one year compared to a study by Mitu et al. that enrolled newly diagnosed hypertensive patients and found a prevalence of non-dippers at 44\% [38]. Nondipping pattern is associated with a longer duration of

Table 3 Distribution of 619 patients in the different arms according to dipping category at baseline and at 6 months

\begin{tabular}{|c|c|c|c|c|}
\hline \multirow[t]{2}{*}{ Treatment arm } & \multicolumn{2}{|c|}{ Baseline dipping category } & \multicolumn{2}{|c|}{6 months dipping category } \\
\hline & $\begin{array}{l}\text { Non-dippers } 487 \\
(79 \%)\end{array}$ & Dippers 132 (21\%) & $\begin{array}{l}\text { Non-dippers } 476 \\
(77 \%)\end{array}$ & Dippers 143 (23\%) \\
\hline Amlodipine and HCTZ, n (\%) & $175(36)$ & $40(30)$ & $166(35)$ & $49(34)$ \\
\hline Amlodipine and PERINDOPRIL, n (\%) & $166(34)$ & $39(30)$ & $157(33)$ & $48(34)$ \\
\hline Perindopril and HCTZ, n (\%) & $146(30)$ & $53(40)$ & $153(32)$ & $46(32)$ \\
\hline
\end{tabular}

McNemar's Chi' ${ }^{2}$ 0.71, $p$ value 0.400 
hypertension [33], probably because the longer the duration, the higher the risk for cardiovascular disease. Third, in the study by Mitu et al., patients with obstructive sleep apnea, diabetes mellitus, arrhythmias were excluded [38], yet these conditions are strongly associated with a nondipping pattern [28, 32, 34, 35], probably accounting for the lower prevalence of non-dippers in these studies. Undiagnosed obstructive sleep apnea, diabetes mellitus and arrhythmias, may contribute to the higher prevalence of the non-dipping pattern in our patients.

Non-dipping pattern was significantly associated with serum sodium greater than $140 \mathrm{mmol} / \mathrm{L}$. Bankir et al. in a large group of subjects from African descent, found that individuals who are poor day time sodium excretors have an increased night time BP and a blunted nocturnal $\mathrm{BP}$ dipping [39]. BP is normally lowest at night, sodium excretion is as well, but if sodium has been retained during the day, BP is adjusted to the higher level needed to eliminate it, and non-dipping results [40]. Hypertensive subjects prone to retain sodium to a degree that affects BP (salt sensitive individuals), are generally non-dippers. Black individuals with hypertension are known to be more salt sensitive than individuals of other races [41-43]. Individuals with salt sensitive hypertension have increased blood pressure levels during nighttime, where a significant sodium load is excreted following pressurenatriuresis mechanisms [44, 45]. Non-dippers retain sodium during the day, probably because of vigorous anti-natriuresis during upright activity, and excrete the excess sodium at night [40]. High intake of sodium may therefore cause non-dipping hypertension [46]. In a study by Uzu et al., sodium restriction in salt sensitive hypertensive patients caused the circadian rhythm of blood pressure to shift from a non-dipping to dipping pattern [47]. Wilson et al. also showed that non-dipping pattern converted to dipping pattern after a high potassium diet in a Black population, which mitigates the effects of high sodium intake [48].

Higher serum sodium levels with non-dipping pattern suggests that there might be high prevalence of hyperaldosteronism among these uncontrolled hypertensive subjects [43]. Studies have showed an association of hyperaldosteronism with non-dipping pattern [49-51]. There is need for further research in the prevalence of hyperaldosteronism in Black African patients with uncontrolled hypertension to personalize treatment.

Office systolic BP was found to be associated with nondipping pattern. This is similar to the study by Bochud et al. that assessed data from 371 individuals of African descent in the Seychelles Islands and 295 Caucasian individuals from Switzerland and found that the white-coat effect occurring in the physician's office is associated with reduced nocturnal BP dipping in two genetically and environmentally different populations [52]. This may mean that patients with high office systolic BP may predict a non-dipping pattern. Patients with a high office systolic BP may need to do an ABPM to determine the dipping pattern.

In this study, office diastolic BP was associated with a non-dipping pattern. A higher systolic BP and lower diastolic BP may estimate a higher pulse pressure or isolated systolic hypertension. This may be comparable to a study in elderly isolated hypertensive patients that found that non-dippers had a higher average pulse pressure of $73 \mathrm{mmHg}$ compared to $64 \mathrm{mmHg}$ in the dippers [53]. The higher pulse pressure among non-dippers could be associated with the higher white coat effect on pulse pressure [54].

Our study findings showed that non-dipping pattern was not significantly associated with older age. This is not consistent with previous studies [30, 31, 33, 38, 55, 56]. We excluded patients with cardiovascular disease and since older age is a known cardiovascular risk factor, most of these patients could have been selected out. We also excluded patients who were on more than one hypertensive drug or who had a systolic blood pressure above $180 \mathrm{mmHg}$ and this could have excluded more patients with severe cardiovascular risk and old age.

Despite some studies showing that metabolic syndrome, dyslipidemia and obesity are associated with nondipping [30,31,33,38,57], our data did not demonstrate significant associations with body mass index, total cholesterol, low density lipoprotein and high density lipoprotein and the non-dipping pattern. This may be due to the fact that our study excluded patients with severe hypertension and cardiovascular disease who usually have dyslipidemia or metabolic syndrome.

Our data did not find any difference between the baseline dipping patterns and the dipping patterns after 6 months of antihypertensive therapy. Despite high serum sodium being associated with night nitriuresis, there was no change in non dipping percentage in the thiazide combination groups. Patients were followed up for a short period of 6 months and this may explain why there was no significant change in the dipping patterns in all three treatment arms. We were unable to determine if taking antihypertensive therapy at bedtime would have caused change of non-dippers to dippers since we did not specify what time patients took their medications. Chronotherapy of hypertension is a new therapeutic option still under study like in the TIME trial [58]. The Hygia Chronotherapy Trial, which reported that taking at least one antihypertensive medication at night instead of on awakening enhanced dipping and reduced relative cardiovascular risk by $45 \%$ [59], has concerns about study design and reporting $[60,61]$. 
Our study results are generalizable to Black African participants with uncontrolled essential hypertension in low-income settings. We considered a single $24 \mathrm{~h} \mathrm{ABPM}$ to classify the patients into non-dippers and dippers. This has been found to be moderately reproducible over time as mentioned in previous studies which recommend a $48 \mathrm{~h}$ ABPM $[62,63]$. However, the second ABPM seems to show similar results to that at baseline. It is also important to note the patients were followed up for a short period of 6 months which made it difficult to assess for cardiovascular events and the effect of treatment on dipping status.

Other limitations; we had a rigid definition of day and night periods in our ABPM, and did not document times of day time napping (siesta), or waking up at night to pass urine (nocturia) during our study. These behavioral phenomena (siesta and nocturia) are more frequent in the studied population because of the hot climate in Sub Saharan Africa and this may account for the finding of very high non-dipping pattern and its "resistance" to pharmacologic therapy.

Afternoon nap, by virtue of its short duration, is devoid of interruptions, and thus can be used as a model for tiled, non-interrupted sleep. BP decline during the afternoon nap lowers the day time average BP and causes misclassification of patients as non-dippers [64-67].

Nocturia results in inclusion of awake BP measurements in the night-time BP measurements and thus raises the average night time $\mathrm{BP}$, causing misclassification of patients as non-dippers $[64,68,69]$.

Daytime and night-time physical activity levels are independently and significantly predictive of the magnitude of the nocturnal dip in BP [69, 70]. Variation in activity may confound interpretation of 24-h ABPM, and contribute to the poor reproducibility of dipper status [70].

\section{Conclusion}

More than three quarters of the Black African patients with uncontrolled hypertension had a non-dipping pattern suggesting a high risk for cardiovascular morbidity and mortality in this cohort. High serum sodium, office systolic BP and diastolic BP were significantly associated with non-dipping pattern. There was no change in dipping pattern following 6 months of antihypertensive therapy. The study shows there is a need for increased utilization of the ABPM in Africa, especially in patients with a high serum sodium and high office systolic BP in order to identify non-dippers. Utilisation of ABPM needs to specify times of physical activity, sleep and frequency of nocturia by the participants. More studies are needed to investigate the need for personalized treatment, like salt restriction and chronotherapy, in non-dippers to convert them to dippers.

\section{Abbreviations}

ABPM: Ambulatory blood pressure monitoring; BMI: Body mass index; BP: Blood pressure; CREOLE: Comparison of Three Combination Therapies in Lowering Blood Pressure in Black Africans; eGFR: Estimated glomerular filtration rate; HCTZ: Hydrochlorothiazide; HDL: High density lipoprotein; LDL: Low density lipoprotein; TG: Triglycerides.

\section{Acknowledgements \\ Research reported in this publication was supported by the Fogarty Inter- national Center and the National Institutes of Health under Award Number D43TW011401. The content is solely the responsibility of the authors and does not necessarily represent the official views of the National Institutes of Health. We acknowledge the late Professor Bongani Mayosi, who championed car- diovascular research in Africa was one of the co principal investigators whose contribution made this trial possible. We also acknowledge the late Veronica Francis who was the CREOLE trial monitor and made this trial possible.}

\section{Authors' contributions}

PMI contributed to the conception and design of the study contributed to data acquisition, secondary data analysis and interpretation, and drafted the manuscript. DBO, ADa, ADz, EJ, OSO, NP, EO, BR, FB, GS and MUS designed study, data acquisition and substantially revised the manuscript. JM did the data analysis and revised the manuscript. DM, CB, BW and JK contributed to the study design and substantially revised the manuscript. SP compiled the data and substantially revised the manuscript. CM contributed to the conception and design of the study, data acquisition and substantially revised the manuscript. All authors read and approved the final manuscript.

\section{Funding}

The CREOLE trial was supported by a project Grant (8264) from the GlaxoSmith-Kline Africa Non communicable Disease Open Lab. The trial drugs were donated by Aspen Pharmacare as part of an educational grant.

\section{Availability of data and materials}

The data that support the findings of this study are available on request from the corresponding author (PMI). The data are not publicly available due to information that could compromise research participant privacy.

\section{Declarations}

\section{Ethics approval}

The primary study protocol was approved by St. Francis Hospital Nsambya Research Ethics Committee (UG-REC-020) and the Uganda National Council for Science and Technology. It was also approved by the institutional review board and ethics committee at each participating centre. The study protoco conforms to the ethical guidelines of the 1975 Declaration of Helsinki as reflected in a priori approval by the institution's human research committee. The subjects were informed about the purpose and procedure of the study; they expressed their written informed consent for the participation, and were allowed to withdraw from the participation at any stage of the study. The participant numbers were used as identifiers instead of their names for confidentiality purpose. No separate IRB approval was sought for this secondary study as no new data collection was conducted and all the analysis conducted fall within the confines of the initial approval.

\section{Consent for publication}

Not applicable.

\section{Competing interests}

The authors declare that they have no competing interests.

\section{Author details}

${ }^{1}$ St. Francis Hospital, Nsambya, Kampala, Uganda. ${ }^{2}$ MakNCD D43 Project, Makerere University College of Health Sciences, Kampala, Uganda. ${ }^{3} \mathrm{Fac}-$ ulty of Health Sciences, Busitema University, Mbale, Uganda. ${ }^{4}$ Department 
of Medicine, Faculty of Clinical Sciences, University of Abuja, Abuja, Nigeria. ${ }^{5}$ University of Abuja Teaching Hospital, Gwagwalada, Nigeria. ${ }^{6}$ Pharmacy, University of Abuja Teaching Hospital, Gwagwalada, Abuja, Nigeria. ${ }^{7}$ Cardiology Unit, Department of Medicine, University of Ibadan/University College Hospital, Ibadan, Nigeria. ${ }^{8}$ Department of Medicine, Bayero University, Aminu Kano Teaching Hospital, Kano, Nigeria. ${ }^{9}$ Division of Nephrology and Hypertension, Cape Town, South Africa. ${ }^{10}$ Hatter Institute of Cardiovascular Research in Africa, Faculty of Health Sciences, University of Cape Town, Cape Town, South Africa. ${ }^{11}$ Imperial Clinical Trials Unit, School of Public Health, Imperial College London, London, UK. ${ }^{12}$ Department of Cardiology, Moi Teaching and Referral Hospital, Eldoret, Kenya. ${ }^{13}$ Department of Clinical Medicine and Therapeutics, University of Nairobi, Nairobi, Kenya. ${ }^{14}$ Eduardo Mondlane University Hospital, Maputo, Mozambique. ${ }^{15}$ Douala General Hospital, Douala, Cameroon.

\section{Received: 11 March 2021 Accepted: 19 May 2021}

\section{Published online: 22 May 2021}

\section{References}

1. Collaborators GRF. Global, regional, and national comparative risk assessment of 84 behavioural, environmental and occupational, and metabolic risks or clusters of risks for 195 countries and territories, 1990-2017: a systematic analysis for the Global Burden of Disease Study 2017. Lancet (London, England). 2018;392(10159):1923.

2. Adeloye D, Basquill C. Estimating the prevalence and awareness rates of hypertension in Africa: a systematic analysis. PLoS ONE. 2014;9(8):e104300.

3. Ataklte F, Erqou S, Kaptoge S, Taye B, Echouffo-Tcheugui JB, Kengne AP. Burden of undiagnosed hypertension in sub-saharan Africa: a systematic review and meta-analysis. Hypertension. 2015;65(2):291-8.

4. Pickering TG, Shimbo D, Haas D. Ambulatory blood-pressure monitoring. N Engl J Med. 2006;354(22):2368-74

5. O'Brien E, Parati G, Stergiou G, Asmar R, Beilin L, Bilo G, et al. European Society of Hypertension position paper on ambulatory blood pressure monitoring. J Hypertens. 2013;31(9):1731-68.

6. Williams B, Mancia G, Spiering W, Agabiti Rosei E, Azizi M, Burnier M, et al. 2018 ESC/ESH Guidelines for the management of arterial hypertension: The Task Force for the management of arterial hypertension of the European Society of Cardiology and the European Society of Hypertension: The Task Force for the management of arterial hypertension of the European Society of Cardiology and the European Society of Hypertension. J Hypertens. 2018;36(10):1953-2041.

7. Stergiou GS, Palatini P, Parati G, O'Brien E, Januszewicz A, Lurbe E, et al. 2021 European Society of Hypertension practice guidelines for office and out-of-office blood pressure measurement. J Hypertens. 2021;39:000.

8. Turner JR, Viera AJ, Shimbo D. Ambulatory blood pressure monitoring in clinical practice: a review. Am J Med. 2015;128(1):14-20.

9. Hermida RC, Smolensky MH, Ayala DE, Portaluppi F. Ambulatory Blood Pressure Monitoring (ABPM) as the reference standard for diagnosis of hypertension and assessment of vascular risk in adults. Chronobiol Int. 2015;32(10):1329-42.

10. Angeli F, Reboldi G, Verdecchia P. Interpretation of ambulatory blood pressure profile: a prognostic approach for clinical practice. J Hypertens. 2015;33(3):454-7.

11. Clement DL, De Buyzere ML, De Bacquer DA, de Leeuw PW, Duprez $\mathrm{DA}$, Fagard $\mathrm{RH}$, et al. Prognostic value of ambulatory blood-pressure recordings in patients with treated hypertension. N Engl J Med. 2003;348(24):2407-15.

12. Mancia G, Verdecchia P. Clinical value of ambulatory blood pressure: evidence and limits. Circu Res. 2015;116(6):1034-45.

13. Verdecchia P. Prognostic value of ambulatory blood pressure : current evidence and clinical implications. Hypertension. 2000;35(3):844-51.

14. O'Brien E, Sheridan J, O'Malley K. Dippers and non-dippers. Lancet. 1988;2(8607):397.

15. Lapinski M, Lewandowski J, Januszewicz A, Kuch-Wocial A, Symonides B, Wocial B, et al. Hormonal profile of dipper and non-dipper patients with essential hypertension. J Hypertens Suppl Off J Int Soc Hypertens. 1993;11(5):S294-5.
16. Vaile JC, Stallard TJ, Al-Ani M, Jordan PJ, Townend JN, Littler WA. Sleep and blood pressure: spontaneous baroreflex sensitivity in dippers and nondippers. J Hypertens. 1996;14(12):1427-32

17. Salles GF, Reboldi G, Fagard RH, Cardoso CR, Pierdomenico SD, Verdecchia $\mathrm{P}$, et al. Prognostic effect of the nocturnal blood pressure fall in hypertensive patients: the ambulatory blood pressure collaboration in patients with hypertension $(\mathrm{ABC}-\mathrm{H})$ meta-analysis. Hypertension. 2016;67(4):693-700.

18. Fagard RH, Thijs L, Staessen JA, Clement DL, De Buyzere ML, De Bacquer DA. Night-day blood pressure ratio and dipping pattern as predictors of death and cardiovascular events in hypertension. J Hum Hypertens. 2009;23(10):645-53.

19. Cuspidi C, Sala C, Tadic M, Gherbesi E, De Giorgi A, Grassi G, et al. Clinical and prognostic significance of a reverse dipping pattern on ambulatory monitoring: an updated review. J Clin Hypertens. 2017;19(7):713-21.

20. Timio M, Venanzi S, Lolli S, Lippi G, Verdura C, Monarca C, et al. " Nondipper" hypertensive patients and progressive renal insufficiency: a 3-year longitudinal study. Clin Nephrol. 1995;43(6):382-7.

21. Mahabala C, Kamath P, Bhaskaran U, Pai ND, Pai AU. Antihypertensive therapy: nocturnal dippers and nondippers. Do we treat them differently? Vasc Health Risk Manag. 2013;9:125-33.

22. Wamba AA, Takah NF, Johnman C. The impact of interventions for the primary prevention of hypertension in Sub-Saharan Africa: a systematic review and meta-analysis. PLoS ONE. 2019;14(7):e0219623.

23. Ojji DB, Mayosi B, Francis V, Badri M, Cornelius V, Smythe W, et al. Comparison of dual therapies for lowering blood pressure in Black Africans. N Engl J Med. 2019;380(25):2429-39.

24. Ojji DB, Poulter N, Damasceno A, Sliwa K, Smythe W, Kramer N, et al. Rationale and design of the comparison of 3 combination therapies in lowering blood pressure in Black Africans (CREOLE study): $2 \times 3$ factorial randomized single-blind multicenter trial. Am Heart J. 2018;202:5-12.

25. Mitu O, Roca M, Gurzu B, Magdalena M, Constantin L, Jitaru A, Al Namat R, Gavril RS, Mitu F. Predictors of the blood pressure non-dipping profile in newly diagnosed hypertensive patients. J Hypertens Res. 2016;2:121.

26. Fagard R, Thijs L, Staessen JA, Clement D, De Buyzere M, De Bacquer D. Night-day blood pressure ratio and dipping pattern as predictors of death and cardiovascular events in hypertension. J Hum Hypertens. 2009;23(10):645-53.

27. Tartan Z, Uyarel H, Kasikcioglu H, Alper AT, Ozay B, Bilsel T, et al. Metabolic syndrome as a predictor of non-dipping hypertension. Tohoku J Exp Med. 2006;210(1):57-66.

28. Suzuki M, Guilleminault C, Otsuka K, Shiomi T. Blood pressure "dipping" and "non-dipping" in obstructive sleep apnea syndrome patients. Sleep. 1996;19(5):382-7.

29. Jaeger BC, Booth JN III, Butler M, Edwards LJ, Lewis CE, Lloyd-Jones DM, et al. Development of predictive equations for nocturnal hypertension and nondipping systolic blood pressure. J Am Heart Assoc. 2020;9(2):e013696.

30. Ben-Dov IZ, Kark JD, Ben-Ishay D, Mekler J, Ben-Arie L, Bursztyn M. Predictors of all-cause mortality in clinical ambulatory monitoring: unique aspects of blood pressure during sleep. Hypertension. 2007;49(6):1235-41.

31. De La Sierra A, Redon J, Banegas JR, Segura J, Parati G, Gorostidi M, et al. Prevalence and factors associated with circadian blood pressure patterns in hypertensive patients. Hypertension. 2009;53(3):466-72.

32. Ma Y, Sun S, Peng C-K, Fang Y, Thomas RJ. Ambulatory blood pressure monitoring in Chinese patients with obstructive sleep apnea. J Clin Sleep Med. 2017;13(3):433-9.

33. Amer H, Awadi M, Shereef A, Mohammad M. Non-dipping phenomenon; Is it reversible in diabetic hypertensive cases. J Clin Exp Cardiol. 2017;8(565):2.

34. Ayala DE, Moyá A, Crespo JJ, Castineira C, Dominguez-Sardina M, Gomara S, et al. Circadian pattern of ambulatory blood pressure in hypertensive patients with and without type 2 diabetes. Chronobiol Int. 2013;30(1-2):99-115.

35. Fogari R, Zoppi A, Malamani GD, Lazzari P, Destro M, Corradi L. Ambulatory blood pressure monitoring in normotensive and hypertensive type 2 diabetics prevalence of impaired diurnal blood pressure patterns. Am J Hypertens. 1993;6(1):1-7.

36. Hebert LA, Agarwal G, Ladson-Wofford SE, Reif M, Hiremath L, Carlton SG, et al. Nocturnal blood pressure in treated hypertensive African Americans 
compared to treated hypertensive European Americans. J Am Soc Nephrol. 1996;7(10):2130-4.

37. Muntner P, Lewis CE, Diaz KM, Carson AP, Kim Y, Calhoun D, et al. Racial differences in abnormal ambulatory blood pressure monitoring measures: results from the Coronary Artery Risk Development in Young Adults (CARDIA) study. Am J Hypertens. 2015;28(5):640-8.

38. Mitu O, Roca M, Gurzu B, Magdalena M, Constantin L, Jitaru A, et al. Predictors of the blood pressure non-dipping profile in newly diagnosed hypertensive patients. 2016

39. Bankir L, Bochud M, Maillard M, Bovet P, Gabriel A, Burnier M. Nighttime blood pressure and nocturnal dipping are associated with daytime urinary sodium excretion in African subjects. Hypertension. 2008:51(4):891-8.

40. Sachdeva A, Weder AB. Nocturnal sodium excretion, blood pressure dipping, and sodium sensitivity. Hypertension. 2006;48(4):527-33.

41. Fray J. Hypertension in blacks: physiological, psychosocial, theoretical, and therapeutic challenges. In: Pathophysiology of hypertension in Blacks. Springer; 1993. p. 3-22.

42. Ergul A. Hypertension in black patients: an emerging role of the endothelin system in salt-sensitive hypertension. Hypertension. 2000;36(1):62-7.

43. Rayner BL, Spence JD. Hypertension in blacks: insights from Africa. LWW; 2017.

44. Ivy JR, Bailey MA. Nondipping blood pressure: predictive or reactive failure of renal sodium handling? Physiology. 2021;36(1):21-34.

45. Burnier M, Coltamai L, Maillard M, Bochud M, editors. Renal sodium handling and nighttime blood pressure. In: Seminars in nephrology. Elsevier; 2007

46. Osanai T, Okuguchi T, Kamada T, Fujiwara N, Kosugi T, Saitoh G, et al. Salt-induced exacerbation of morning surge in blood pressure in patients with essential hypertension. J Hum Hypertens. 2000;14(1):57-64.

47. Uzu T, Ishikawa K, Fujii T, Nakamura S, Inenaga T, Kimura G. Sodium restriction shifts circadian rhythm of blood pressure from nondipper to dipper in essential hypertension. Circulation. 1997:96(6):1859-62.

48. Wilson DK, Sica DA, Miller SB. Effects of potassium on blood pressure in salt-sensitive and salt-resistant black adolescents. Hypertension. 1999;34(2):181-6.

49. Gregoire JR, editor. Adjustment of the osmostat in primary aldosteronism. In: Mayo clinic proceedings. Elsevier; 1994.

50. Uzu T, Nishimura M, Fujii T, Takeji M, Kuroda S, Nakamura S, et al. Changes in the circadian rhythm of blood pressure in primary aldosteronism in response to dietary sodium restriction and adrenalectomy. J Hypertens. 1998:16(12):1745-8

51. Kusunoki H, Iwashima Y, Kawano Y, Hayashi S, Kishida M, Horio T, et al. Circadian hemodynamic characteristics in hypertensive patients with primary aldosteronism. J Hypertens. 2018;36(11):2260-8.

52. Bochud M, Bovet P, Vollenweider P, Maillard M, Paccaud F, Wandeler G, et al. Association between white-coat effect and blunted dipping of nocturnal blood pressure. Am J Hypertens. 2009;22(10):1054-61.

53. Zain-El Abdin M, Snincak M, Pahuli K, Solarova Z, Hrabcakova P. Nondipping morning blood pressure and isolated systolic hypertension in elderly. Bratisl Med J Bratisl Lek Listy. 2013;114(3):150-4.

54. Ben-Dov IZ, Perk G, Ben-Arie L, Mekler J, Bursztyn M. Pulse pressure is more susceptible to the white coat effect than is systolic blood presure: observations from real-life ambulatory blood pressure monitoring. Am Hypertens. 2004;17(6):535-9.
55. Vasunta R-L, Kesäniemi YA, Ylitalo A, Ukkola O. Nondipping pattern and carotid atherosclerosis in a middle-aged population: OPERA Study. Am J Hypertens. 2012;25(1):60-6.

56. Dai S, Huang B, Zou Y, Liu Y. Associations of dipping and non-dipping hypertension with cardiovascular diseases in patients with dyslipidemia. Arch Med Sci AMS. 2019;15(2):337.

57. Hermida RC, Chayán L, Ayala DE, Mojón A, Fontao MJ, Fernández JR. Relationship between metabolic syndrome, circadian treatment time, and blood pressure non-dipping profile in essential hypertension. Chronobiol Int. 2011;28(6):509-19.

58. Rorie DA, Rogers A, Mackenzie IS, Ford I, Webb DJ, Willams B, et al. Methods of a large prospective, randomised, open-label, blinded endpoint study comparing morning versus evening dosing in hypertensive patients: the Treatment In Morning versus Evening (TIME) study. BMJ Open. 2016;6(2):e010313.

59. Hermida RC, Crespo JJ, Domínguez-Sardiña M, Otero A, Moyá A, Ríos MT, et al. Bedtime hypertension treatment improves cardiovascular risk reduction: the Hygia Chronotherapy Trial. Eur Heart J. 2020;41(48):4565-76.

60. Kreutz R, Kjeldsen SE, Burnier M, Narkiewicz K, Oparil S, Mancia G. Blood pressure medication should not be routinely dosed at bedtim. We must disregard the data from the HYGIA project. Blood Press. 2020;29(3):135-6.

61. Guthrie G, Poulter N, Macdonald T, Ford I, Mackenzie I, Findlay E, et al. Chronotherapy in hypertension: the devil is in the details. Eur Heart J. 2020:41(16):1606-7.

62. Omboni S, Parati G, Palatini P, Vanasia A, Muiesan ML, Cuspidi C, et al. Reproducibility and clinical value of nocturnal hypotension: prospective evidence from the SAMPLE study. J Hypertens. 1998;16(6):733-8.

63. Parati G, Staessen JA. Day-night blood pressure variations: mechanisms, reproducibility and clinical relevance. J Hypertens. 2007;25(12):2377-80.

64. Ben-Dov IZ, Bursztyn M. Daytime sleeping and night-time urinating obscure normal dipping. Nephrol Dial Transplant. 2006;21(1):226-7.

65. Perk G, Mekler J, Ishay DB, Bursztyn M. Non-dipping in diabetic patients: insights from the siesta. J Hum Hypertens. 2002;16(6):435-8.

66. Stergiou G, Malakos J, Zourbaki A, Achimastos A, Mountokalakis T. Blood pressure during siesta: effect on 24-h ambulatory blood pressure profiles analysis. J Hum Hypertens. 1997;1 1(2):125-31.

67. Bursztyn M, Mekler J, Wachtel N, Ben-Ishay D. Siesta and ambulatory blood pressure monitoring Comparability of the afternoon nap and night sleep. Am J Hypertens. 1994;7(3):217-21.

68. Matsumoto T, Tabara Y, Murase K, Setoh K, Kawaguchi T, Nagashima S, et al. Nocturia and increase in nocturnal blood pressure: the Nagahama study. J Hypertens. 2018;36(11):2185-92.

69. Agarwal R, Light RP, Bills JE, Hummel LA. Nocturia, nocturnal activity, and nondipping. Hypertension. 2009;54(3):646-51.

70. Leary AC, Donnan PT, MacDonald TM, Murphy MB. Physical activity level is an independent predictor of the diurnal variation in blood pressure. J Hypertens. 2000;18(4):405-10

\section{Publisher's Note}

Springer Nature remains neutral with regard to jurisdictional claims in published maps and institutional affiliations.

Ready to submit your research? Choose BMC and benefit from:

- fast, convenient online submission

- thorough peer review by experienced researchers in your field

- rapid publication on acceptance

- support for research data, including large and complex data types

- gold Open Access which fosters wider collaboration and increased citations

- maximum visibility for your research: over 100M website views per year

At BMC, research is always in progress.

Learn more biomedcentral.com/submissions 